\title{
Second Language Learners' and Teachers' Perceptions of Delayed Immediate Corrective Feedback in an Asynchronous Online Setting: An Exploratory Study
}

\author{
Laia Canals, Gisela Granena, Yucel Yilmaz, \\ $\mathcal{E}$ Aleksandra Malicka
}

Online language courses that rely on asynchronous teacher-learner communication face a practical problem when it comes to the provision of immediate corrective feedback by the teacher in oral interaction tasks. In this learning context, learners can still communicate synchronously and record their interaction without the teacher being present, but feedback by the teacher will be delayed in time. Research indicates that the effectiveness of feedback decreases as the time between the error and the correction increases and that immediate feedback is more effective (Arroyo \& Yilmaz, 2018; Shintani \& Aubrey, 2016). In this exploratory study conducted at an online university, we implemented a novel type of feedback we referred to as delayed immediate corrective feedback (DICF) and analyzed second language learners' and teachers' perceptions regarding its effectiveness and usefulness. Our goal was to assess the feasibility of implementing this type of feedback in our context and, ultimately, in other contexts where communication between teachers and learners takes place asynchronously. DICF was provided by teachers orally via screencast video. Learners and teachers' perceptions were collected via two separate questionnaires. The results showed that teachers and learners responded positively to DICF and several potential benefits were identified.

Les cours de langue en ligne qui s'appuient sur la communication asynchrone enseignant-apprenant rencontrent un problème pratique quand vient le temps de fournir de la rétroaction corrective immédiate par l'enseignant lors des tâches d'interaction orale. Dans ce contexte d'apprentissage, les apprenants peuvent toujours communiquer de manière synchrone et enregistrer leur interaction sans que l'enseignant soit présent, mais la rétroaction de l'enseignant sera décalée dans le temps. La recherche indique que l'efficacité de la rétroaction diminue au fur et à mesure que le temps entre l'erreur et la correction augmente, et que la rétroaction immédiate est plus efficace (Arroyo \& Yilmaz, 2018; Shintani \& Aubrey, 2016). Dans cette étude exploratoire menée auprès d'une université en ligne, nous avons mis en place une nouvelle forme de rétroaction, que nous avons appelée rétroaction corrective immédiate retardée (RCIR), et nous avons analysé les perceptions des apprenants de langue seconde et des enseignants quant à son utilité et à son efficacité. Notre objectif était d'évaluer la faisabilité de mettre en place ce type de 
rétroaction dans notre contexte, et par extension, dans d'autres contextes où la communication entre apprenants et enseignants se passe de manière asynchrone. La RCIR a été fournie oralement par des enseignants à l'aide de vidéos d'écrans. Les perceptions des apprenants et des enseignants ont été recueillies dans deux questionnaires distincts. Les résultats ont montré qu'apprenants et enseignants ont réagi à la RCIR de manière positive et plusieurs avantages potentiels ont été identifiés.

Keywords: corrective feedback, feedback timing, computer-mediated communication, video feedback, task-based language teaching, distance language teaching

In synchronous online interactions and traditional face-to-face settings, corrective feedback $(\mathrm{CF})$, i.e., the reactions language learners receive from their interlocutors showing that the learners' language production is not target-like, can be provided immediately. However, in asynchronous language teaching contexts, feedback is provided in a delayed fashion, with a lapse of time between learners' performance and teachers' feedback. This lack of immediateness stands in contrast to some of the empirical research findings in this area which indicate that immediate feedback maximizes learning opportunities (Arroyo \& Yilmaz, 2018; Henderson, 2020; Li et al., 2016).

Given the relevance of asynchronous delivery in online language learning programs (Brigman \& Petty, 2013; Oztok et al., 2013), there is a need for a practical solution that can make delayed feedback more similar to immediate feedback. One way of approaching this issue, which has previously been used to provide feedback on errors in writing (Ducate \& Arnold, 2012; Vincelette \& Bostic, 2013), is by inserting feedback instances into the original video recording using screencast software and then having students relive their oral performance. After a couple of semesters using this modality of feedback, we surveyed both language learners and teachers in selected English-asa-foreign-language (EFL) courses at an online university regarding this approach to feedback by means of a questionnaire that provided us with insightful information about its affordances. This paper reports on the results of the questionnaire as a first step towards the implementation of this novel type of $\mathrm{CF}$ in the language courses offered at the online university where the study was conducted.

\section{Interaction and Corrective Feedback in Synchronous Computer-Mediated Communication}

Ever since people started to use computers to interact with one another, synchronous computer-mediated communication (SCMC), real-time 
communication through instant messaging tools, has attracted the attention of second language acquisition (SLA) researchers. The topic continues to draw attention due to three recent developments. First, SCMC has started to figure more prominently in second language (L2) teaching as a number of language programs (see Blake, 2009; Canals \& Granena, 2020) have integrated SCMC tasks into their curriculum. Second, carrying out some real-life tasks via SCMC has become increasingly more common (González-Lloret, 2014). We use SCMC tools to correspond with our personal contacts using applications such as Skype or WhatsApp, interact with customer service representatives (e.g., to make changes to airline reservations), or collaborate with other players in massively multiplayer online games (e.g., World of Warcraft). Third, synchronous online teaching using tools such as Zoom has become more widespread due to the current global pandemic of coronavirus disease (COVID-19).

Communication in SCMC can be text-based (or text chat), audio-based, video-based, or multimodal (a combination of text, audio, or video). Research has shown that chat modality can influence the amount and nature of interactional features that occur naturally in communication. Yanguas (2010) compared the amount of negotiated interaction in audio chat, videoconferencing, and face-to-face communication between dyads of learners of Spanish. He found that the groups produced comparable amounts of negotiated interaction. Ziegler and Phung (2019) compared the amount of various interactional features, such as comprehension checks, confirmation checks, clarification requests, explicit feedback, recasts, modified output, and language-related episodes in text chat, audio chat, videoconferencing, and multimodal chat between EFL learners and two experienced English language teachers and native speakers of English. While the results showed minimal differences between multimodal chat, videoconferencing, and audio chat, text chat yielded the lowest number of interactional features overall. Ziegler and Phung (2019) also administered a questionnaire to determine learners' perceptions of different SCMC modalities, which revealed that learners preferred videoconferencing most and found it the easiest for task completion. Other studies focused on the effectiveness of feedback delivered via videoconferencing. Monteiro (2014) compared the relative effectiveness of metalinguistic feedback versus recasts provided through videoconferencing on learners' English past tense errors and found that neither group outperformed the no-feedback control group (i.e., both feedback types were equally ineffective). Rassaei (2017), who compared the effectiveness of recasts delivered via videoconferencing versus recasts delivered via faceto-face communication, showed that both videoconferencing and face-toface feedback groups performed significantly better than the no-feedback control group, but that there were no significant differences between the two feedback groups. 
Providing synchronous or immediate feedback is not always possible for teachers in distance language learning contexts because of scheduling problems between teachers and students. In such contexts, asynchronous or delayed feedback might be a more viable alternative. We are not aware of any distance language learning studies that have investigated the role of teacher-provided delayed feedback in L2 learning, but there are studies that investigated the role of delayed feedback provided by learners to learners. Studies examining the effectiveness of asynchronous learner-to-learner feedback via emails have demonstrated that this feedback had a positive impact on grammar, spelling, and vocabulary (Vinagre \& Muñoz, 2015; Ware \& O'Dowd, 2008). These studies, however, did not focus on the role of asynchronous feedback provided on errors that had taken place during synchronous interaction. Bower and Kawaguchi (2011) documented the use of this type of delayed feedback. In their study, Japanese-English tandem partners, learning each other's language, provided delayed feedback to each other through emails on their partner's errors that had occurred during their interaction in SCMC. The study found quantitative and qualitative differences between the corrective feedback provided in the synchronous and asynchronous mode. Quantitatively, significantly more feedback was provided in the asynchronous mode. Qualitatively, the feedback in the asynchronous mode included metalinguistic explanations in addition to reformulations. However, the study did not provide any information regarding the effectiveness of delayed feedback or whether learners had positive views about its use. In addition, the delayed feedback used in Bower and Kawaguchi's (2011) study was in the written mode. This shows that there is a clear lack of research investigating the extent to which video-based delayed feedback is effective in L2 learning and positively viewed by learners in distance language learning programs.

\section{Corrective Feedback and the Role of Feedback Timing}

There is a consensus among SLA researchers operating within the cognitiveinteractionist research paradigm (e.g., Doughty, 2001; Long, 1996) that CF facilitates L2 acquisition. Several meta-analyses (e.g., Goo et al., 2015; Lyster \& Saito, 2010; Mackey \& Goo, 2007; see also a book-length treatment of corrective feedback by Nassaji \& Kartchava, 2017) synthesizing the research on $\mathrm{CF}$ have provided supportive evidence for this position, demonstrating that the magnitude of the effect of CF on L2 learning was medium to large.

A primary theoretical motivation for the use of CF comes from the interaction hypothesis (Long, 1996), which posits that conversational interaction facilitates L2 learning by making linguistic input comprehensible. The interaction hypothesis also holds that $\mathrm{CF}$ that occurs during conversational interaction contributes to L2 learning because it attracts learners' attention to the formal aspects of language and may lead to useful cognitive processes, 
such as noticing (Schmidt, 2001). In addition, the focus on form (FonF) perspective, which is grounded in the interaction hypothesis, provides further theoretical support for the use of $\mathrm{CF}$ by claiming that instruction should briefly draw learners' attention to formal elements of language when there is a perceived need for an intervention (Long, 1991; Long \& Robinson, 1998). The output hypothesis (Swain, 1985, 1995) also assigns a primary role for corrective feedback in interactional exchanges. According to this hypothesis, feedback asking learners to revise their nontarget-like attempts helps them notice linguistic forms, test hypotheses, and increase metalinguistic awareness.

Doughty (2001), an advocate for the FonF perspective, has claimed that learners benefit from CF, especially from recasts (reformulations of learners' incorrect utterances that preserve the intended meaning), by mentally comparing in their working memory their intention, their output, and the feedback. According to Doughty (2001), one can talk about the existence of a cognitive window of opportunity during which a mental comparison can be made most effectively and which "may be as long as 40 seconds" (p. 226).

Two previous studies (Li et al., 2016; Quinn, 2014) investigated whether timing has an impact on the effectiveness of feedback provided during or after oral communicative tasks. Quinn (2014) (see also Quinn \& Nakata, 2017, for a review of studies on timing and corrective feedback) examined the acquisition of the English passive construction employing a pretest-immediate posttestdelayed posttest design with three groups (immediate feedback, delayed feedback, control). All learners carried out three communicative tasks with the researcher and the delayed group received feedback at the end of each task, whereas the immediate group received feedback immediately after their errors. The feedback provided was a hybrid form that included both a prompt and a reformulation. The results showed that feedback was ineffective regardless of timing because there was no statistically significant difference between the feedback groups and the control group learning outcomes. $\mathrm{Li}$ et al. (2016) followed a quasi-experimental design, including a pretest, an immediate posttest, and a delayed posttest. The linguistic target was the English past passive. During the treatment, learners were asked to perform two narration tasks. Learners' errors in the immediate condition were treated with a hybrid feedback strategy including a prompt and a reformulation. The same hybrid feedback strategy was used to treat errors in the delayed group, which received feedback at the end of the second task. First, they were reminded of their error with an explicit statement such as, "you said 'the driver wanted to run away, but he stopped by a policeman.' Can you say it correctly?" Later, they were provided with a reformulation ("he was stopped"). The results of the study showed advantages for the immediate group on one of the outcome measures (i.e., grammaticality judgment test).

Several studies have focused on the relative effectiveness of immediate and delayed feedback in the context of text chat. Arroyo and Yilmaz (2018) 
investigated the role of $\mathrm{CF}$ timing in the acquisition of Spanish noun-adjective gender agreement. Forty-five Spanish learners carried a communicative task via text chat in one of three groups (immediate, delayed, control). The immediate group received reformulations immediately after their errors. The delayed group received feedback at the end of the task when they were provided with an electronic document that listed the errors they had made during the task and their target-like reformulations. The results indicated that the immediate group outperformed the delayed group on an oral production test, but there were no differences between the two feedback groups on a grammaticality judgment test.

Yilmaz and Sağdıç (2019) and Arroyo and Yilmaz (2017) were based on the same data set as Arroyo and Yilmaz (2018). Arroyo and Yilmaz (2017) investigated the interaction between language analytic ability measured through LLAMA_F and the effects of feedback timing, whereas Yilmaz and Sağdıç (2019) investigated the interaction between inhibitory control measured through the Flanker test and the effects of feedback timing. The results of these studies showed that neither language analytic ability nor inhibitory control moderated the effect of feedback timing.

Henderson $(2019,2020)$ carried out two studies focusing on the effects of feedback timing. Henderson (2019) followed a pretest-posttest experimental design with three groups (immediate, delayed, control) and focused on the acquisition of Spanish vocabulary. Feedback, which included the repetition of the learner's error and the correct reformulation of the error, was provided during or after a one-way information gap task with the researcher via text chat. The study showed no feedback timing effect even though both feedback groups outperformed the control group in an oral picture description test. Henderson (2020) investigated not only the effect of feedback timing on three dependent variables (learners' linguistic improvement, noticing, and preferences), but also the interactions between communication mode, working memory, and feedback timing. The study followed a pretestimmediate posttest-delayed posttest design with four groups (face-to-face immediate, face-to-face delayed, text chat immediate, and text chat delayed). The feedback included both the repetition and the reformulation of the error. Immediate feedback was provided during two oral story-retell tasks, whereas delayed feedback was presented at the end of each task. The results showed that immediate feedback led to significantly more noticing and linguistic gains than the delayed feedback, and these effects did not interact with working memory or communication mode.

Based on the most recent studies investigating the role of feedback timing (e.g., Arroyo \& Yilmaz, 2018; Henderson, 2020; Li et al., 2016), one can tentatively conclude that the timing of CF seems to have an effect on L2 learning outcomes (but see Quinn \& Nakata, 2017, for an earlier review on the topic that reached a different conclusion). Specifically, immediate feedback in these studies has been associated with greater learning gains. This suggests 
that the short time lapse between feedback and error in immediate feedback conditions might have helped learners make the mental comparison between their intention, their output, and the input conveyed through feedback (Doughty, 2001).

\section{Corrective Feedback and the Role of Learners' and Teachers' Perceptions}

In the area of CF, learners' and teachers' perceptions have been investigated from a variety of perspectives. Some of the issues that have attracted researchers' attention are whether learners perceive error correction as positive and useful (e.g., Amrhein \& Nassaji, 2010; Loewen et al., 2009), what type of feedback they prefer and on what type of errors (e.g., Kartchava, 2016), and whether there is a link between learners' beliefs about the importance of feedback and the extent to which they notice feedback (e.g., Kartchava, 2012).

Amrhein and Nassaji (2010) compared L2 learners' and teachers' opinions and preferences for different amounts and types of written CF. Regarding the amount of $\mathrm{CF}$, the results of the questionnaires showed that the learners preferred to be corrected on all major errors, while the teachers preferred correcting only the errors that interfered with comprehension. Regarding types of $\mathrm{CF}$, both learners and teachers agreed that the most useful type of feedback consisted of clues or directions on how to fix errors, but teachers were significantly more positive on this item than learners. Overall, the study showed some significant differences between teachers' and learners' opinions. Teachers preferred being selective with error correction and expected learners to self-correct, while learners preferred large quantities of $\mathrm{CF}$ and expected teachers to provide explicit and explanatory $\mathrm{CF}$, rather than having to make their own corrections. Amrhein and Nassaji concluded that openly discussing the use of CF with learners could help resolve potential disagreements between teachers' and learners' preferences and opinions.

Loewen et al. (2009) investigated the beliefs of L2 learners about the role of grammar instruction and error correction in L2 learning. Participants were 754 students enrolled in different L2 or foreign language courses at various levels of instruction. Data were analyzed quantitatively via a factor analysis and a discriminant function analysis and qualitatively. The results showed that learners studying different target languages differed significantly in their responses to the questionnaire. The learners of English as an L2 (ESL) were the least positive about the role of grammar in L2 learning and considered grammar less important than foreign language learners. Regarding error correction, ESL learners had a less positive attitude towards error correction than foreign language learners. The study concluded that learners' beliefs can distinguish L2 learners studying different target languages, particularly ESL learners and foreign language learners. 
Kartchava (2016) compared the beliefs about oral CF in two English language learning contexts, EFL and ESL. The results of the beliefs questionnaire showed that learners, regardless of their learning context, expected CF and considered it important. The two groups of learners were also similar in that they preferred to be corrected by means of recasts and prompts. Finally, the two groups also agreed that the types of errors on which they preferred to receive $\mathrm{CF}$ were recurrent errors or errors that interfered with comprehension. The role of gender, however, differed in the two groups. In the ESL group, gender determined the likelihood of recasts being preferred as a correction method, whereas, in the EFL group, gender (together with the number of languages spoken) influenced the type of errors that learners thought needed to be corrected.

Kartchava (2012) investigated the relationships between type of feedback, noticing, beliefs about feedback, and L2 improvement. One hundred and ninety-seven learners of English in Quebec received oral corrective feedback (or no feedback) depending on their group assignment (recasts, prompts, mixed [recasts + prompts], and control). A 40-item questionnaire was used to measure learners' beliefs about feedback. L2 improvement was measured through two written production tasks administered at three different time points (immediately before, immediately after, and eight weeks after the treatment), whereas noticing was measured through immediate verbal protocols. The study revealed a complex picture regarding the role of learners' beliefs and the extent to which learners benefit from feedback. It was found that believing that feedback is important, as well as believing in recasts as an effective feedback technique significantly correlated with noticing of feedback. However, believing in prompts as an effective feedback technique was not related to learners' noticing. Also, beliefs about feedback were not related to learners' L2 improvement.

This brief review of studies on L2 learners' perceptions of CF shows that learners have clear ideas about error correction, about what they prefer or see as beneficial, and that instruments such as questionnaires are an effective tool to investigate learners' perceptions. The importance of perceptions from the point of view of L2 learning lies in the fact that there may be links between how learners perceive $\mathrm{CF}$ and the way they process or notice CF. From the point of view of teaching, learner perceptions can inform L2 instruction by helping teachers adapt their CF practices. The studies conducted in this area have all investigated face-to-face L2 learning contexts. Learners' perceptions of technology-mediated feedback and the type of CF provided in online learning contexts have only been investigated in general, in relation to feedback provided in a variety of higher education courses (see Mahoney et al., 2019, for a research synthesis), but not in relation to feedback provided in language courses. 


\section{The Present Study}

In online language courses where communication between teachers and learners takes place only asynchronously, any $\mathrm{CF}$ instances by the teacher will reach learners in a delayed manner. In addition to being delayed in terms of timing, feedback instances in this asynchronous context are typically provided all at once, intensively, and isolated from the broader context (i.e., the task) where the error was made (e.g., Arroyo \& Yilmaz, 2018; Henderson, 2020; Li et al., 2016). The teacher may send written reports or voice recordings to each individual student with a list of errors and feedback instances. From the point of view of FonF, as originally defined by Long (1991), one could argue that this approach to the provision of feedback may prevent learners from establishing effective form-meaning connections. According to Long (2015), "focus on form involves reactive use of a wide variety of pedagogic procedures to draw learners' attention to linguistic problems in context, as they arise during communication" (p. 317). CF can be explicit or implicit, but, according to Long, it should be provided in context and in response to a problem that arises during a communicative exchange so that the learner can simultaneously process form and meaning while vested in the exchange, "motivated to learn what is needed and attending to the response" (p. 27).

One way of providing delayed CF instances in context is by recreating immediacy as part of delayed feedback, a practice we refer to as delayed immediate corrective feedback (DICF), a type of delayed feedback that incorporates features of immediate feedback. Learners are asked to complete and video record a task in pairs in real time using a videoconferencing tool. Then, the language teacher edits the video recording using a screencast tool and inserts video-based CF instances immediately after nontarget-like productions. The learners watch the resulting video clip where they see the original interaction and the teacher's CF video-comments inserted throughout the interaction.

This type of delayed feedback has several advantages. First, it allows the teacher to insert any type of CF by stopping the video immediately after an error and inserting an implicit or explicit correction. Second, this CF is provided in context and recreates the real-time event. Third, it can be easily juxtaposed to learners' nontarget-like utterances, allowing them to make a cognitive comparison between their own form and the corrected form side by side (Doughty, 2001). Finally, by having the opportunity to see and listen to themselves in real-life interaction, learners may find the replay motivating and may be more likely to attend to the corrections and engage the cognitive mechanisms that contribute to language acquisition.

The strengths we see in DICF are all based on theoretical justifications for CF. There is clearly a need to empirically test the effects of DICF on L2 learning outcomes and we are currently investigating this issue in a different study (Canals et al., 2019). In addition to investigating the effects of DICF 
on actual learning outcomes, it is also relevant to explore L2 learners' and teachers' perceptions regarding the effectiveness and efficiency of this type of feedback in order to evaluate the practicality of DICF and the extent to which it can be positively received. Learners' perceptions have been described as a key variable that can inform instructional practices (e.g., Chen et al., 2016). Disconnects between learners' perceptions of instructional techniques and teachers' expectations can impair learning effectiveness (e.g., Amrhein \& Nassaji, 2010). In distance learning environments where students' motivation and engagement are essential (Dixson, 2010; Stockwell, 2013), perceived effectiveness among learners can be particularly important. In a synthesis of the literature on video feedback in higher education, Mahoney et al. (2019) concluded that students liked video feedback and that this had had positive effects on student engagement with feedback as shown by longer reviewing of the feedback and multiple viewings.

In the case of teachers, perceived efficiency regarding aspects such as time consumption and technical expertise (e.g., Cunningham, 2019) can affect teachers' willingness to incorporate this novel type of feedback into their teaching practice. By collecting data on learners' and teachers' perceptions, we can begin to assess the practicality of implementing this novel CF type in an actual language learning environment.

The study addressed two research questions:

1. How useful do learners find DICF in oral interaction tasks?

2. How do teachers evaluate their experience with DICF?

\section{Method}

\section{Learning Context}

This study was conducted at a fully online university in Spain. The EFL courses, which constitute the context of the present study, are semester-long courses that follow a task-based language teaching methodology. These courses are taught in virtual classrooms with a teacher that communicates asynchronously with students. Despite the fact that teachers and students do not communicate in real time, students are required to complete a minimum of two compulsory oral interaction tasks synchronously in pairs or small groups, regardless of the level. The teachers provide feedback and assess task performance individually. The oral interaction tasks in which DICF was implemented in the present study are carried out synchronously via Skype. Task-based oral interaction between students is the only synchronous component in the asynchronous language learning courses offered by the university. They are usually two-way, split-information decision-making, jigsaw, or opinion-giving tasks. The communication between the students 
takes place over Skype, and the students need to record their session in a video format, using the Skype built-in recorder. When students have completed the task, they make their recording available to their teacher, who provides feedback on their performance within two or three weeks after the task completion. This feedback generally includes corrective feedback, metalinguistic explanations alongside comments on task accomplishment, and tips on how to improve linguistic performance. The feedback teachers give may take different forms, such as audio feedback or written comments. Regardless of the CF method used, there is a significant time gap between any errors students might have made during the task and their teacher's feedback.

\section{Participants}

Ten ELF teachers and 66 EFL learners took part in this exploratory study. The courses from which data were collected included A1, A2, and C1 EFL levels. These are the Common European Framework of Reference (CEFR) levels equivalent to 2-3.5, 3.5-5 and 10-11 levels of the Canadian Language Benchmarks (CLB), respectively (North \& Piccardo, 2018). There were eight female and two male teachers. Their ages ranged between 35 and 55, and they were all experienced online language teachers, having taught online at the university for more than three years and up to 10 years. The learners were all older than 18 . No other demographic information was collected. Out of the 66 learners, 32 were enrolled in the advanced course (C1) and 34 in the beginners' courses (A1 or A2). Four of the participating teachers were teaching the $\mathrm{C} 1$ course, three teachers were teaching $\mathrm{A} 1$, and three others were teaching A2.

We tested the implementation of DICF in these levels because these English courses are not taken to fulfill a language requirement for a degree at the university and, therefore, they provided us with a low-stakes context to implement a new pedagogical intervention. Additionally, the number of students in the A1, A2 and C1 levels, a few hundred students, made the use of DICF more manageable than in the other English courses offered by the university, which usually have thousands of students every term. Despite the differences in the proficiency levels, the DICF tool and the procedures followed to give feedback in the oral interaction tasks were the same across the levels.

\section{Data Collection}

The data were collected over two consecutive semesters. We surveyed teachers and learners after teachers had had the opportunity to provide DICF in two different oral interaction tasks over the course of a semester. Instead of recording an audio message or providing written comments like in previous terms, teachers were asked to use a screencasting tool (Screencast-O-Matic) to record themselves while watching their students' videos. This tool allowed 
teachers to play the learners' video-recorded task, stop the video when they wanted to provide feedback, and insert a video recording of themselves providing the feedback right after the learners' nontarget-like utterances or right after an aspect the teachers thought would be important to comment on. This edited video recording was then sent to the students together with their grades after two or three weeks. This way, learners were able to watch a recording of their performance in the oral interaction task, as well as video comments from their teacher inserted at relevant points of the interaction. Learners were not required to either watch the video recording or answer the questionnaire that was administered as part of this study. However, given that oral interaction in these courses is graded, we expected most of the students to be motivated enough as to watch the video in order to understand their grade. We also expected that those learners who answered the questionnaire and gave their opinion on DICF would be the learners who had watched the video recording.

\section{Instruments}

Two anonymous questionnaires (see Appendices A and B, respectively) were developed to find out teachers' and learners' opinions about the use of a screencasting tool to provide DICF. The questionnaires were set up as an anonymous online survey and took about five minutes to fill out. The learners' questionnaire included 17 questions: eight multiple choice questions and nine open-ended questions. The teachers' questionnaire comprised a total of 20 questions: nine multiple choice questions and 11 open-ended questions. One question in each of the questionnaires asked about the perceived effectiveness of DICF, the type of feedback investigated here.

After designing a first version of the questionnaires with questions loosely based on Ozkan and Koseler's (2009) model for the evaluation of e-learning systems, both questionnaires were submitted to a group of experts (university professors coordinating other EFL courses at the same institution) in order to assess the ability of each item to measure the effectiveness and usefulness of the feedback. The group of experts suggested revisions to some sentences and suggested adding the "not-applicable" option in questions 3 and 5 of the learners' questionnaire. The questionnaires were revised and edited accordingly.

Learners were asked about their perceptions regarding the usefulness of the feedback they received. The questionnaire also asked them to reflect on the benefits of receiving DICF compared with the type of feedback they used to receive in the past. Specifically, they were surveyed about several aspects of the DICF: whether it was easier to understand, faster and easier to access, and more useful, which correspond to Ozkan and Koseler's (2009) system quality, content quality, learner perspective, and supportive issues. The learners' questionnaire was administered in three language versions. A1 and A2 level 
learners answered the questionnaire in Spanish or Catalan (whichever they preferred) while C1 learners answered it in English (we assumed that C1 learners would be able to answer this type of questionnaire in the target language). Questions 1, 3 and 5 in the learners' questionnaire addressed the usefulness and perceived effectiveness of the feedback provided. The scale used was different for the first item of the questionnaire (question 1) because the first item aimed at assessing the overall perceived usefulness of DICF and having a 5-point scale allowed for greater response discrimination levels. The rest of the items asked about specific aspects of DICF and a rating scale with fewer points was adopted so that the scale could be easily understood by respondents. Three-point scales are relatively quick to use and, in general, less time-consuming.

The teachers' questionnaire was designed following the same criteria. Teachers were surveyed about the efficiency of the tool and the procedures of providing feedback in this manner in terms of time and ease of use, which correspond to Ozkan and Koseler's (2009) system quality and service quality. They were also asked about the possibility of continuing to use DICF in the future (supportive issues, according to Ozkan \& Koseler, 2009). The teachers' questionnaire was administered in English because it was the target language of the course they taught. In this case, questions 3 and 5 addressed the efficiency of the feedback provided on a 3-point scale of 0 to 2 .

Both questionnaires included open-ended comment sections following each of the items, as well as an open-ended final comments section. Means and standard deviations were calculated for each item. The responses to the open-ended questions were collated and relevant comments were gathered in order to complement and add nuance to the quantitative data.

\section{Results}

This section will first provide an account of the learners' perceptions regarding the usefulness of the DICF they received, as detailed in the first research question. To address the second research question, we will lay out the results of the questionnaire that was administered to the teachers, which surveyed them about their experience with this new way of providing feedback. In this study, we only report on the answers to those questions that could inform us about how this new way of providing or receiving feedback was perceived in terms of its usefulness. Those questions inquiring about specific characteristics of the feedback were not analyzed in this study because the purpose of the study was to assess the practicality of this new approach to delayed feedback and the extent to which it could be positively received by teachers and learners. Finally, data from the three proficiency levels surveyed were merged to obtain an overall picture of participants' perceptions regarding DICF $^{1}$. 
Table 1 displays learners' answers regarding the effectiveness and usefulness of DICF.

Table 1

Learners' Responses to the Questionnaire

\begin{tabular}{|c|c|c|}
\hline & $M$ & $S D$ \\
\hline $\begin{array}{l}\text { 1. How useful were the individual video feedback messages } \\
\text { from your teacher this semester?* }\end{array}$ & 4.61 & 0.74 \\
\hline $\begin{array}{l}\text { 2. How useful was it compared with previous semesters or } \\
\text { other language classes you took? }\end{array}$ & 1.80 & 0.40 \\
\hline $\begin{array}{l}\text { 3. How effective was this way of receiving feedback in terms } \\
\text { of understanding the feedback? }\end{array}$ & 1.97 & 0.17 \\
\hline $\begin{array}{l}\text { 4. How effective was this way of receiving feedback in terms } \\
\text { of accessing the feedback faster? }\end{array}$ & 1.71 & 0.52 \\
\hline $\begin{array}{l}\text { 5. How effective was this way of receiving feedback in terms } \\
\text { of the relevance of the feedback itself (the type of errors } \\
\text { corrected, and the way errors were corrected)? }\end{array}$ & 1.88 & 0.33 \\
\hline $\begin{array}{l}\text { 6. How effective was this way of receiving feedback in terms } \\
\text { of the possibility of accessing and watching it later on? }\end{array}$ & 1.88 & 0.38 \\
\hline
\end{tabular}

The first item asked learners to rate the usefulness of DICF and this was measured on a scale of 1 to 5 , where 1 was not useful and 5 was very useful. Items 2 to 6 asked students to rate the usefulness or perceived effectiveness of the feedback received on a scale of 0 to 2 , where 0 referred to DICF not being perceived as useful and 2 to being perceived as useful.

Regarding the overall usefulness of DICF, learners $(N=66)$ responded that this way of receiving feedback was overall very useful $(M=4.61, S D$ $=.74)$. When asked to compare DICF with the feedback they had received in previous semesters, which was not video feedback provided on their recordings but audio or written feedback provided as a separate file, learners indicated that they found DICF more useful $(M=1.80, S D=.40)$. Specifically, learners expressed almost unanimously $(M=1.97, S D=.17)$ that feedback provided in this way eased their comprehension of the feedback. They also found this feedback convenient to access $(M=1.71, S D=.52)$ and relevant $(M$ $=1.88, S D=.33)$. Finally, learners appreciated the possibility to access DICF as many times as they needed $(M=1.88, S D=.38)$.

When asked about the number of times they watched the video recording where DICF was provided (see Figure 1), over half of the learners (i.e., 54\%) reported having watched it twice and almost one-fourth of the learners (i.e., $23.8 \%)$ reported having watched it three times. Fewer learners reported having watched the video recording a single time (i.e., 20.6\%), and only one person reported not having watched it at all. 
Figure 1

Times Learners Reported Having Watched the Feedback Received

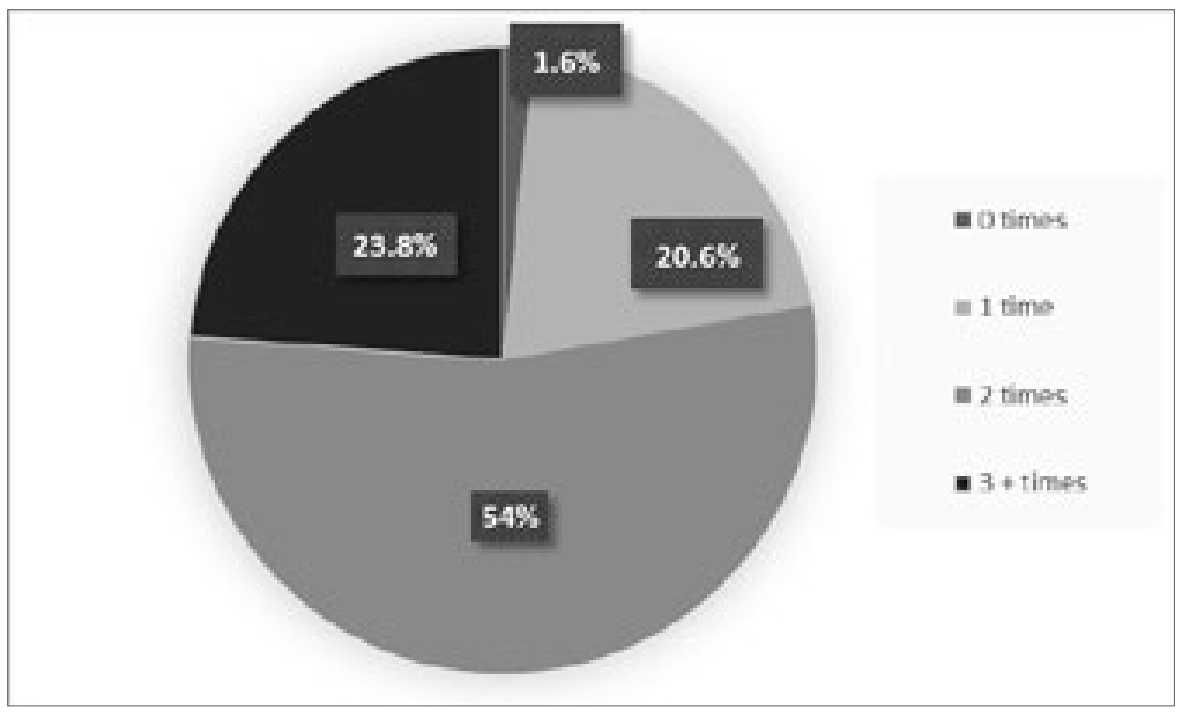

The analysis of the open-ended questions confirmed the perceptions indicated above regarding the usefulness of the feedback. Some learners pointed out the fact that this feedback seemed easier and faster to access ("It's more effective and faster, both in terms of watching and easiness to access it"). Other learners indicated that they felt DICF was more interactive ("It feels closer, useful and makes you interact more with the teacher"). Some other learners commented on the benefits of receiving the feedback in context and juxtaposed with the error ("It is a good system that allows you to detect specific errors at the exact point where they occur," "watching the video you know perfectly well where you have failed and the intonation you have to do, and listening to what the teacher says in English is also a learning experience," and "this is an excellent initiative because it stops [the video] when needed and [it helps] contextualize the correction a lot").

\section{Teachers' Perceptions}

The teachers' questionnaire rated all items on a 3-point scale (0 to 2). When teachers $(N=10)$ were asked about whether they thought DICF was a more efficient way of providing feedback (i.e., less time-consuming), most of them agreed with the statement $(M=1.60, S D=.70)$, as shown in Figure 2 below. 
Figure 2

Teachers' Responses about the Efficiency of DICF

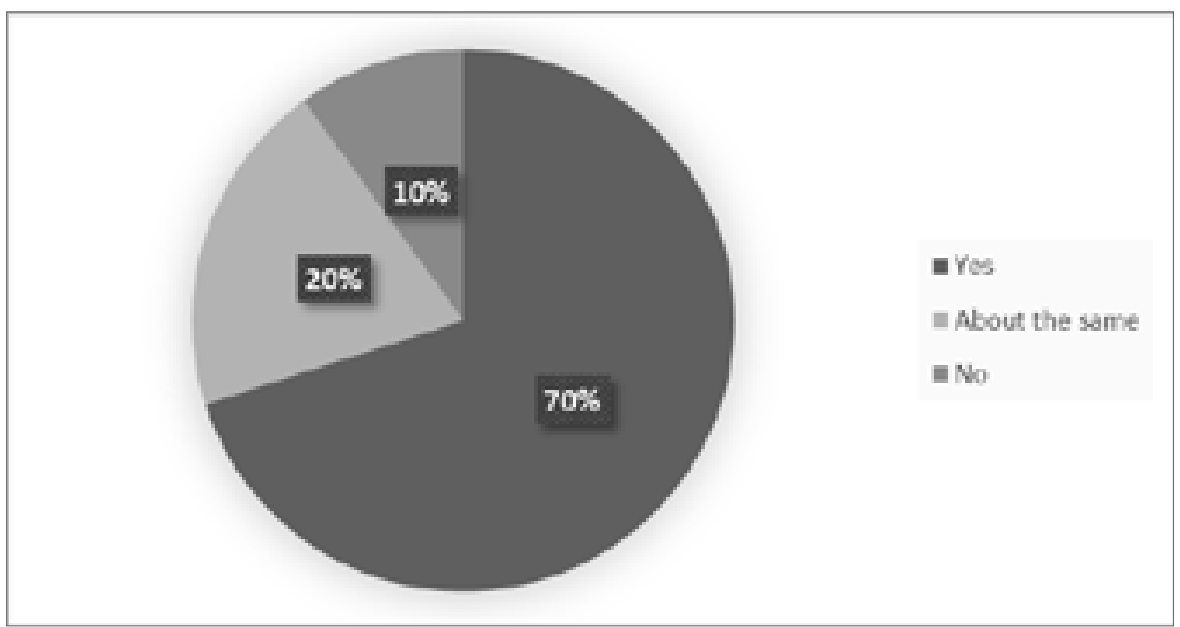

Regarding the usability of the tool, teachers also agreed that it was easier to use $(M=1.50, S D=.71)$ than the tools (word documents or audio messages) they had been using in previous semesters to provide feedback via audio recordings or written comment, as can be observed in Figure 3.

Figure 3

Teachers' Responses about Ease of Use of Screencasting Tool

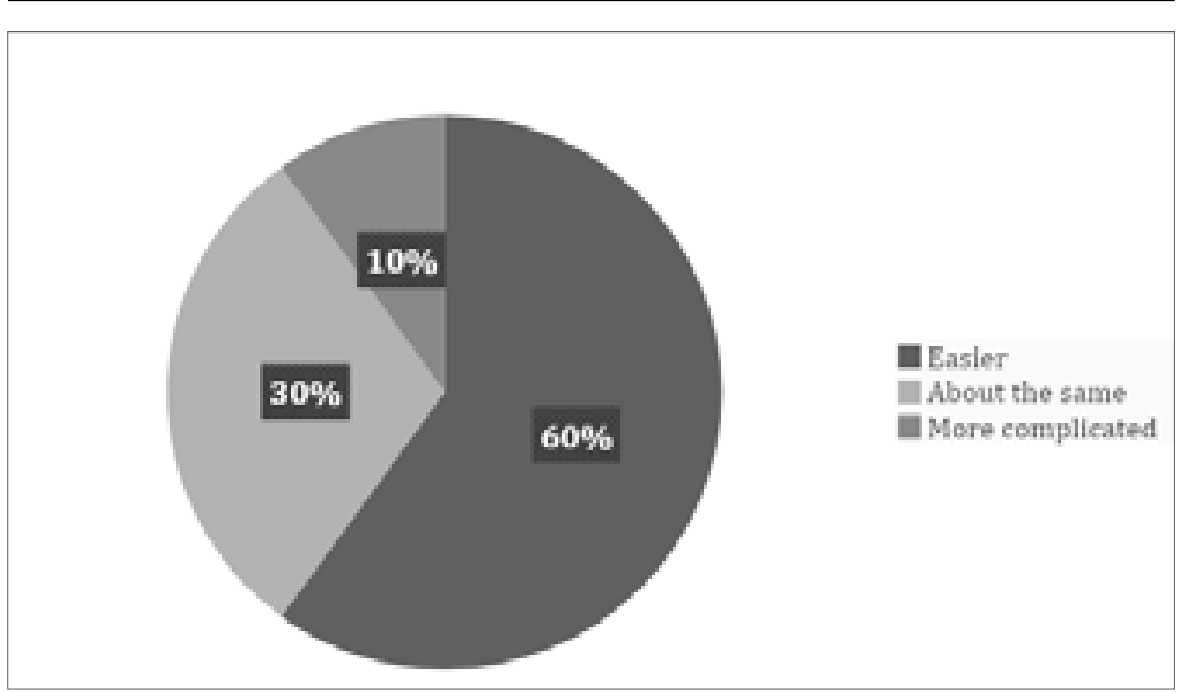


Finally, when asked whether they would like to continue giving DICF, nine out of 10 responded positively. The only teacher who did not want to continue using this type of feedback indicated that "correcting too many wrong things is demoralising for students" and that "it's more effective to note down serious and frequent errors. Then point them out to students at the end."

An analysis of the teachers' open-ended comments further confirmed that they found DICF efficient and convenient to use. Some teachers reported that DICF was "easier and more practical." Others also pointed out other benefits of DICF in terms of the interactive potential it offers, indicating that they found it "more interactive and personal" and that "it felt like speaking directly to the students."

Some teachers valued positively the fact that DICF allowed them to provide feedback instances in context and as errors arose: "I could stop every time a student said something wrong and correct it." Two other teachers indicated that their experience with DICF was "similar to face-to-face teaching; I can give immediate feedback just when they make the mistake" and pointed out that they saw advantages to the use of DICF because they could "provide corrections without interrupting the student." And finally, another teacher commented on the potential benefits of allowing learners to observe how their language production led to feedback: "I think it is very positive that students see their own performance at the same time that they are getting feedback from the teacher."

\section{Discussion}

The first research question in this study asked about learners' perceptions regarding the usefulness of DICF in oral interaction tasks. The results revealed that in general learners had positive views about DICF. Specifically, learners found DICF useful, and considered it an improvement over other ways of receiving feedback they had experienced in the past (i.e., audio recordings and written comments). They also thought that DICF was relevant, convenient, quick, and easy to access.

This perceived usefulness of DICF is particularly relevant for several reasons. First, because there may be links between learners' positive perceptions of $\mathrm{CF}$ and the extent to which they notice feedback (e.g., Kartchava, 2012). Second, because positive opinions about how CF is provided can influence learners' motivation and, in online learning environments such as the one under study, students' motivation and engagement are essential (Stockwell, 2013; Dixson, 2010).

The fact that DICF is video-based may have contributed to learners' positive views. Studies on technology-mediated text and screencast feedback in the area of written CF (e.g., Cunningham, 2019; Ducate \& Arnold, 2012; Elola \& Oskoz, 2016²; Vincelette \& Bostic, 2013) have shown that, although 
students see utility in both types of feedback, they prefer screencast video feedback for its usability, efficiency and heightened understanding. Other studies on the use of different types of video-based feedback (talking heads, screencasts, or other combinations) have also shown a preference for video feedback over written feedback among learners (e.g., Crook et al., 2012; Grigoryan, 2017). It should be noted, however, that new technological tools can have a positive impact on learners' engagement and result in an increased positive response simply due to the novelty effect (Clark, 1983).

A unique feature of the delayed feedback investigated in the present study is that it offers the opportunity for learners to re-watch the video and the feedback multiple times. The results obtained showed that most of the learners (i.e., $75 \%$ ) took advantage of such an opportunity by watching the feedback twice or three times, while only $20 \%$ of them watched the feedback a single time. The possibility to easily access the feedback as many times as needed could be considered a unique affordance of video-based DICF which face-to-face feedback in a regular classroom setting would be lacking. This constitutes an instance where the possibilities of the virtual language learning modality surpass the possibilities of face-to-face instruction, at least as far as feedback in oral interaction is concerned. The possibility of re-watching videos has been identified as an advantage of video-based feedback in previous research as well (e.g., Crook et al., 2012) and several studies have shown that watching a video multiple times is a common practice (e.g., Grigoryan, 2017; Vincelette \& Bostic, 2013).

The second research question asked about teachers' evaluation of their experience with DICF. Similar to learners' responses, teachers' experience with DICF was also mostly positively rated. They agreed that it was easy to provide and non-time-consuming. Only one of the 10 teachers surveyed expressed disagreement with the use of DICF, perhaps due to the fact that novelty has the potential to be met with risk-aversion (Howard, 2013) or reluctance and instill feelings of resistance to change (Mumtaz, 2000) by teachers. This teacher thought that it was more useful and less intrusive to provide CF on serious and recurrent errors all at once at the end of the task. The opposing view offered by this teacher raises the practical question of whether teachers should correct according to what they think is most beneficial, according to what students prefer, or according to what research has shown to be useful. In the area of written CF, Armhein and Nassaji (2010) found that, contrary to research findings suggesting that allowing learners to self-correct is useful, students and many teachers in their study preferred repeatedly correcting errors each time they occur. In order to deal with this and similar challenges in error correction pedagogy, Armhein and Nassaji recommended teachers to openly discuss their CF practices with students and called for research to find out how to address such differences for optimal pedagogy.

In general, the teachers' open-ended comments pointed towards some of the potential benefits of DICF. One of these benefits was related to the 
temporal distribution of the feedback and to the fact that it was provided in the broader context of the interaction when an error occurred. This perceived benefit is in line with Long's (1991) understanding of the role of context as a factor that can facilitate form-function connections because the learner has prior comprehension of the message. Another potential benefit of DICF that teachers commented on was the fact that it was perceived as a real interaction between learners and their instructor. This is another unique feature of DICF, in contrast to audio-based or written-based delayed feedback. In their review of research conducted on video-based feedback, Mahoney et al. (2019) pointed out the increased interactive and dialogical possibilities that video feedback offers and highlighted its potential to strengthen learner-instructor relationships and to promote learner engagement in the feedback process. Such potential was even greater in the case of screencast modalities which have a more dialogic nature.

Teachers' open-ended comments in the present study provide some support to our operationalization of DICF as a type of delayed feedback that incorporates features of immediate feedback. By recreating immediacy conditions and giving learners the opportunity to relive the interaction, this approach to delayed feedback is able to convey needed information about the target language in context, can facilitate form-function mapping, as well as the comparison of error and correction, since the incorrect and correct utterances are juxtaposed. These are some of the probable psycholinguistic advantages of immediate implicit CF defended by Long (1996) that would also apply to DICF.

Further research is needed, however, to determine whether incorporating features that characterize immediate $\mathrm{CF}$ into delayed $\mathrm{CF}$ has an impact on the actual effectiveness of delayed CF and on the way DICF is processed. This type of research is needed to triangulate findings from studies investigating learners' and teachers' perceptions of $\mathrm{CF}$, such as the present one, which rely on self-reported data. The present study was exploratory in nature and had several limitations. It relied on a convenience sample and a small number of participants from a variety of proficiency levels. In addition, a single instrument (i.e., a questionnaire) was used without determining its validity or reliability, which limits the generalizability of the findings. Also, the use of 3-point scales for some of the items might have lowered the discriminability power of those items. Finally, and due to the anonymity of the questionnaires, biographical information about the participants could not be gathered, which prevented us from exploring the participants' perceptions in depth. Future studies should include a more robust set of instruments to be able to collect teachers' and learners' impressions in a more reliable manner, for instance, conducting focus groups and interviews using stimulated recall protocols. 


\section{Conclusion and Pedagogical Implications}

Virtual classrooms have become a common instructional context. Language teachers in this context are faced with practical needs and challenges that provide a relevant arena to link research and practice. This exploratory study addressed the particular challenge of providing $\mathrm{CF}$ in an asynchronous language learning environment, where $\mathrm{CF}$ is characterized by being delayed in time. We implemented a novel type of technology-mediated feedback which is delayed in time but which incorporates features of immediate feedback and investigated teachers' and learners' opinions about this CF in an exploratory study. The results showed that DICF was perceived as useful by learners and as efficient by teachers. DICF was further perceived as being closer to dialogical or interactive forms of providing feedback, which could make learners and teachers feel closer in an asynchronous environment where social presence is crucial for student engagement (see Garrison et al., 2010).

The results of this exploratory study have pedagogical implications for online language learning, both for computer-assisted language learning and computer-mediated communication. First, the positive views of DICF observed among teachers and learners support the feasibility of implementing this novel type of feedback in an actual language learning environment. Second, by blurring the line between synchronous and asynchronous feedback, DICF opens the door to more meaningful and dialogical feedback practices in online language learning settings. Finally, face-to-face settings could also benefit from these affordances if teachers were to audio or video record the learners' interactions in class and provide feedback at a later time. Teachers would be able to provide feedback without having to interrupt the flow of learners' interaction while on task. Learners, on the other hand, could find DICF motivating and, as a result, pay more attention to the feedback, thereby engaging the cognitive mechanisms that facilitate L2 acquisition.

\section{Notes:}

1. The three proficiency groups were comparable in their responses to each item, according to a series of one-way ANOVAs $(\mathrm{p}>.05)$.

2. There is some research which focuses on video-based feedback on language learning such as Ducate and Arnold (2012) or Elola and Oskoz (2016). However, their line of research is not entirely relevant to our study because these studies focus mostly on using screencasting software on written texts and our current research examines corrective video-based feedback on oral interactive tasks. The other research studies which use video-based feedback cited in the discussion section come from studies in other disciplines where feedback is less granular and more holistic than in language learning settings. This makes the comparison difficult and limits the relevance of discussing these studies in detail as background for the current study. 


\section{The Authors}

Laia Canals currently holds a lecturer position at the Centre for Modern Languages at the Universitat Oberta de Catalunya. Her research addresses technology enhanced task-based language learning, development of L2 through interaction in collaborative tasks in computermediated communication settings, the development of intercultural communicative competence, the development of digital skills and online language teacher education.

Gisela Granena is an associate professor in the School of Arts and Humanities at the Universitat Oberta de Catalunya. Her research focuses on cognitive individual differences in both instructed and naturalistic contexts; aptitude-treatment interaction; task-based language teaching; measures of implicit and explicit language knowledge, as well as the effects of early and late bilingualism on long-term second language achievement.

Yucel Yilmaz is an associate professor of Second Language Studies at Indiana University. His research focuses on second language interaction and corrective feedback; computer-mediated communication; task-based language teaching; individual differences in second language acquisition; and explicit and implicit learning processes.

Aleksandra Malicka holds an MA and PhD in Applied Linguistics from the University of Barcelona. Her areas of expertise include second language acquisition, task-based language teaching, and research synthesis and meta-analysis. She has worked as an English teacher and lecturer for the past nine years, and she currently holds an English lecturer position at the Universitat Oberta de Catalunya.

\section{References}

Amrhein, H. R., \& Nassaji, H. (2010). Written corrective feedback: What do students and teachers prefer and why? Canadian Journal of Applied Linguistics, 13, 95-127.

Arroyo, D. C., \& Yilmaz, Y. (2017). The role of language analytic ability in the effectiveness of different feedback timing conditions. In L. Gurzynski-Weiss (Ed.), Expanding individual difference research in the interaction approach: Investigating learners, instructors, and other interlocutors (pp. 71-97). Amsterdam: John Benjamins. https://doi.org/10.1075/aals.16.04arr

Arroyo, D. C., \& Yilmaz, Y. (2018). An open for replication study: The role of feedback timing in synchronous computer-mediated communication. Language Learning, 68(4), 942-972. https:// doi.org/10.1111/lang. 12300

Blake, R. J. (2009). The use of technology for second language distance learning. The Modern Language Journal, 93, 822-835. https://doi.org/10.1111/j.1540-4781.2009.00975.x

Bower, J., \& Kawaguchi, S. (2011). Negotiation of meaning and corrective feedback in Japanese/ English eTandem. Language Learning \& Technology, 15(1), 41-71. http://dx.doi.org/10125/44237

Brigman, M. J., \& Petty, T. M. (2013). Perceptions of preparation of online alternative licensure teacher candidates. In R. Hartshorne, T. Heafner, \& T. Petty (Eds.), Teacher education programs and online learning tools: Innovations in teacher preparation (pp. 38-58). Hershey, PA: IGI Global Publishing.

Canals, L., Granena, G., Yilmaz, Y., \& Malicka, A. (2019, March). Reproducing immediacy conditions when giving delayed corrective feedback and its implications in online language learning settings. Paper presented at the American Association for Applied Linguistics Conference, Atlanta, GA.

Canals, L., \& Granena, G. (2020). Shifting paradigms: Online language teacher education for online language teachers. In H.-S Kang, D.-S. Shin, \& T. Cimasko (Eds.), Online education for teachers of English as a global language (pp. 105-131). Routledge.

Chen, S., Nassaji, H., \& Liu, Q. (2016). EFL learners' perceptions and preferences of written corrective feedback: A case study of university students from Mainland China. Asian-Pacific 
Journal of Second and Foreign Language Education, 1:5, pp. 1-17. DOI: 10.1186/s40862-0160010-y

Clark, R. E. (1983). Reconsidering research on learning from media. Review of Educational Research, 53(4), 445-459. https://doi.org/10.3102/00346543053004445

Crook, A., Mauchline, A., Maw, S., Lawson, C., Drinkwater, R., Lundqvist, K., Orsmond, P., Gomez, S., \& Park, J. (2012). The use of video technology for providing feedback to students: Can it enhance the feedback experience for staff and students? Computers $\mathcal{E}$ Education, 58(1), 386-396. DOI: 10.1016/j.compedu.2011.08.025

Cunningham, K. J. (2019). Student perceptions and use of technology-mediated text and screencast feedback in ESL writing. Computers and Composition, 52, 222-241. DOI: 10.1016/j.compcom.2019.02.003

Dixson, M. D. (2010). Creating effective student engagement in online courses: What do students find engaging? Journal of the Scholarship of Teaching and Learning, 10(2), 1-3. https:// scholarworks.iu.edu/journals/index.php/josotl/article/view/1744

Doughty, C. J. (2001). Cognitive underpinnings of focus on form. In P. Robinson (Ed.), Cognition and second language instruction (pp. 206-257). Cambridge: Cambridge University Press.

Ducate, L., \& Arnold, N. (2012). Computer-mediated feedback: Effectiveness and student perceptions of screen-casting software versus the comment function. Technology across Writing Contexts and Tasks, 10, 31-56. https://doi.org/10.1016/j.jslw.2018.05.005

Elola, I., \& Oskoz, A. (2016). Supporting second language writing using multimodal feedback. Foreign Language Annals, 49(1), 58-74. DOI: 10.1111/flan.12183

Garrison, D. R., Anderson, T., \& Archer, W. (2010). The first decade of the community of inquiry framework: A retrospective. The Internet and Higher Education, 13(1-2), 5-9. DOI: https://doi. org/10.1016/j.iheduc.2009.10.003

González-Lloret, M. (2014). The need for needs analysis in technology-mediated TBLT. In M. González-Lloret \& L. Ortega (Eds.), Technology-mediated TBLT (pp. 23-50). Amsterdam: John Benjamins. https://doi.org/10.1075/tblt.6.02gon

Goo, J., Granena, G., Yilmaz, Y., \& Novella, M. (2015). Implicit and explicit instruction in L2 learning. In P. Rebuschat (Ed.), Implicit and explicit learning of languages (pp. 443-482). Amsterdam: John Benjamins. https://doi.org/10.1075/sibil.48.18goo

Grigoryan, A. (2017). Audiovisual commentary as a way to reduce transactional distance and increase teaching presence in online writing instruction: Student perceptions and preferences. Journal of Response to Writing, 3(1), 83-128. Corpus ID: 64568171

Henderson, C. (2019). The effect of feedback timing on L2 Spanish vocabulary acquisition in synchronous computer-mediated communication. Language Teaching Research, 1-24. DOI: $10.1177 / 1362168819832907$

Henderson, C. (2020). Perfect timing? Exploring the effects of immediate and delayed corrective feedback, communication mode, and working memory on the acquisition of Spanish as a foreign language $[\mathrm{PhD}$ dissertation, Indiana University]. DOI: 10.1177/1362168819832907

Howard, S. K. (2013). Risk-aversion: Understanding teachers' resistance to technology integration. Technology, Pedagogy and Education, 22(3), 357-372. http://dx.doi.org/10.1080/14759 39X.2013.802995

Kartchava, E. (2012). Notice ability of corrective feedback, L2 development and learner beliefs [PhD dissertation, Université de Montréal, Canada].

Kartchava, E. (2016). Learners' beliefs about corrective feedback in the language classroom: Perspectives from two international contexts. TESL Canada Journal, 33(2), 19-45.

Li, S., Zhu, Y., \& Ellis, R. (2016). The effects of the timing of corrective feedback on the acquisition of a new linguistic structure. The Modern Language Journal, 100(1), 276-295. https://doi. org $/ 10.1111 /$ modl.12315

Loewen, S., Li, S., Fei, F., Thompson, A., Nakatsukasa, K., Ahn, S., \& Chen, X. (2009). Second language learners' beliefs about grammar instruction and error correction. The Modern Language Journal, 93(1), 91-104. 
Long, M. H. (1991). Focus on form: A design feature in language teaching methodology. In K. de Bot, R. B. Ginsberg, \& C. Kramsch (Eds.), Foreign language research in cross-cultural perspective (pp. 39-52). Amsterdam: John Benjamins. http://dx.doi.org/10.1075/sibil.2.07lon

Long, M. H. (1996). The role of the linguistic environment in second language acquisition. In W. Ritchie \& T. Bhatia (Eds.), Handbook of second language acquisition (pp 413-468). Cambridge, MA: Academic Press.

Long, M. H. (2015). Second language acquisition and task-based language teaching. Malden, MA: Wiley-Blackwell.

Long, M. H., \& Robinson, P. (1998). Focus on form: Theory, research, and practice. In C. J. Doughty \& J. Williams (Eds.), Focus on form in classroom SLA (pp. 15-41). Cambridge: Cambridge University Press.

Lyster, R., \& Saito, K. (2010). Oral feedback in classroom SLA: A meta-analysis. Studies in Second Language Acquisition, 32(2), 265-302. DOI: https://doi.org/10.1017/S0272263109990520

Mackey, A., \& Goo, J. (2007). Interaction research in SLA: A meta-analysis and research synthesis. In A. Mackey (Ed.), Conversational interaction in SLA: A collection of empirical studies (pp. 408452). New York: Oxford University Press.

Mahoney, P., Macfarlane, S., \& Ajjawi, R. (2019). A qualitative synthesis of video feedback in higher education. Teaching in Higher Education, 24(2), 157-179. https://doi.org/10.1080/1356 2517.2018.1471457

Monteiro, K. (2014). An experimental study of corrective feedback during video-conferencing. Language Learning \& Technology, 18(3), 56-79. http://dx.doi.org/10125/44384

Mumtaz, S. (2000). Factors affecting teachers' use of information and communications technology: A review of the literature. Journal of Information Technology for Teacher Education, 9(3), 319-342. DOI: $10.1080 / 14759390000200096$

Nassaji, H., \& Kartchava, E. (Eds.). (2017). Corrective feedback in second language teaching and learning: Research, theory, applications, implications (Vol. 66). New York: Routledge.

North, B., \& Piccardo, E. (2018). Aligning the Canadian Language Benchmarks (CLB) to the Common European Framework of References (CERF). Research Report. Toronto: Centre for Canadian Language Benchmarks. https://www.language.ca/aligning-clb-and-cefr/ Accessed 1/30/2020

Ozkan, S., \& Koseler, R. (2009). Multi-dimensional students' evaluation of e-learning systems in the higher education context: An empirical investigation. Computers $\mathcal{E}$ Education, 53(4), 1285-1296.

Oztok, M., Zingaro, D., Brett, C., \& Hewitt, J. (2013). Exploring asynchronous and synchronous tool use in online courses. Computers \& Education, 60(1), 87-94. DOI: 10.5555/2397199.2397296

Quinn, P. (2014). Delayed versus immediate corrective feedback on orally produced passive errors in English [PhD dissertation, University of Toronto, Canada]. URI: http://hdl.handle. net $/ 1807 / 65728$

Quinn, P., \& Nakata, T. (2017). The timing of oral corrective feedback. In H. Nassaji \& E. Kartchava (Eds.), Corrective feedback in second language teaching and learning (pp. 51-64). New York: Routledge.

Rassaei, E. (2017). Video chat vs. face-to-face recasts, learners' interpretations and L2 development: A case of Persian EFL learners. Computer Assisted Language Learning, 30(1-2), 133-148. https:// doi.org/10.1080/09588221.2016.1275702

Schmidt, R. (2001). Attention. In P. Robinson (Ed.), Cognition and second language instruction (pp. 3-32). Cambridge, UK: CUP.

Shintani, N., \& Aubrey, S. (2016). The effectiveness of synchronous and asynchronous written corrective feedback on grammatical accuracy in a computer-mediated environment. The Modern Language Journal, 100(1), 296-319. DOI: 10.1111/modl.12317

Stockwell, G. (2013). Technology and motivation in English-language teaching and learning. In International perspectives on motivation (pp. 156-175). London: Palgrave Macmillan. https:// doi.org/10.1057/9781137000873_9

Swain, M. (1985). Communicative competence: Some roles of comprehensible input and 
comprehensible output in its development. In S. Gass \& C. Madden (Eds.), Input in second language acquisition (pp. 235-253). Rowley, MA: Newbury House.

Swain, M. (1995). Three functions of output in second language learning. In G. Cook \& B. Seidlhofer (Eds.), Principle and practice in applied linguistics: Studies in honour of H.G. Widdowson (pp. 125-144). Oxford: Oxford University Press.

Vinagre, M., \& Muñoz, B. (2011). Computer-mediated corrective feedback and language accuracy in telecollaborative exchanges. Language Learning $\mathcal{E}$ Technology, 15(1), 72-103. http://dx.doi. org $/ 10125 / 44238$

Vincelette, E. J., \& Bostic, T. (2013). Show and tell: Student and instructor perceptions of screencast assessment. Assessing Writing, 18(4), 257-277. https://doi.org/10.1016/j.asw.2013.08.001

Ware, P., \& O'Dowd, R. (2008). Peer feedback on language form in telecollaboration. Language Learning \& Technology, 12(1), 43-63. http://dx.doi.org/10125/44130

Yanguas, Í. (2010). Oral computer-mediated interaction between L2 learners: It's about time! Language Learning \& Technology, 14(3), 72-93. http://dx.doi.org/10125/44227

Yilmaz, Y., \& Sağdıç, A. (2019). The interaction between inhibitory control and corrective feedback timing. ITL-International Journal of Applied Linguistics, 170(2), 204-227. https://doi.org/10.1075/ itl.19010.yil

Ziegler, N., \& Phung, H. (2019). Technology-mediated task-based interaction: The role of modality. ITL-International Journal of Applied Linguistics, 170(2), 251-276. https://doi. org/10.1075/itl.19014.zie 


\section{Appendix A}

\section{Teachers' questionnaire}

I would like you to think back and evaluate Screencast-O-Matic for giving feedback for the group speaking tasks.

1. How did you give feedback in previous semesters? Tick all that apply.

Using RAC/REC's recording tool to record videos

Using RAC/REC's recording tool to record audios

Recording videos offline and uploading them to the RAC/REC

Recording audios offline and uploading them to the RAC/REC

2. Specify other ways you were giving feedback.

3. Was using Screencast-O-Matic a quicker way of giving feedback compared with previous terms?

Yes

About the same

No

4. Comments.

5. How easy was Screencast-O-Matic compared with the way you were giving feedback last term?

Easier

About the same

More complicated

6. Comments.

7. Can you think of other ways of using Screencast-O-Matic to provide feedback that would help you save time?

8. How effective was Screencast-O-Matic for providing feedback to your students in terms of...

\begin{tabular}{|l|l|l|l|l|}
\hline & Effective & Neutral & Not effective & N/A \\
\hline giving explicit corrective feedback? & & & & \\
\hline giving implicit corrective feedback? & & & & \\
\hline correcting pronunciation? & & & & \\
\hline
\end{tabular}




\begin{tabular}{|l|l|l|l|l|}
\hline giving feedback on content? & & & & \\
\hline $\begin{array}{l}\text { giving feedback on task } \\
\text { achievement? }\end{array}$ & & & & \\
\hline $\begin{array}{l}\text { highlighting areas they need to } \\
\text { improve on? }\end{array}$ & & & & \\
\hline
\end{tabular}

9. Comments.

10. Which type of feedback did you give to your students when using Screencast-O-Matic? Tick all that apply.

Explicit corrective feedback

Implicit corrective feedback

Correcting pronunciation

Feedback on content

Feedback on task achievement

Areas to improve

11. Comments.

12. In previous semesters, what type of feedback did you mostly give to your students? Tick all that apply.

Explicit corrective feedback

Implicit corrective feedback

Correcting pronunciation

Feedback on content

Feedback on task achievement

Areas to improve

13. Comments.

14. The use of Screencast-O-Matic can facilitate providing ... Tick all that apply. individual feedback.

whole-class feedback.

feedback in pairs.

oral feedback on students' oral contributions.

oral feedback on students' written contributions. 
Other:

15. Any other?

16. Did you explain to your students what type of feedback they would receive and why, either in the past or now?

Only in the past

Only recently

Both in the past and recently

No

17. If you did, explain briefly how you did that.

18. Would you like to continue using this way of giving feedback or would you rather go back to doing what you were doing before?

Continue to use this way of giving feedback

Go back to the way I was giving feedback before

19. Why? Why not?

20. Do you have any other comments you'd like to add about giving feedback and/or about using Screencast-O-Matic for other purposes in the course?

\section{Appendix B}

\section{Learners' questionnaire}

I would like you to think back and evaluate the feedback you received for the Skype tasks this term.

1. How useful were the individual video feedback messages from your teacher this semester?

$\begin{array}{lllllll}\text { Not useful } & 1 & 2 & 3 & 4 & 5 & \text { Very useful }\end{array}$

2. Comments.

3. How useful was it compared with previous semesters or other language classes you took? More useful

About the same

Less useful

N/A 
4. Comments.

5. How effective was this way of receiving feedback in terms of...

\begin{tabular}{|l|l|l|l|l|}
\hline & Effective & Neutral & $\begin{array}{l}\text { Not } \\
\text { effective }\end{array}$ & N/A \\
\hline understanding the feedback? & & & & \\
\hline accessing the feedback faster? & & & & \\
\hline $\begin{array}{l}\text { relevance of the feedback itself (the things } \\
\text { and way your teacher corrected)? }\end{array}$ & & & & \\
\hline understanding pronunciation mistakes? & & & & \\
\hline $\begin{array}{l}\text { possibility of accessing and watching it } \\
\text { later on? }\end{array}$ & & & & \\
\hline highlighting areas you needed to improve? & & & & \\
\hline
\end{tabular}

6. Comments.

7. Which type of feedback you think you mostly received from your teacher's videos? Tick all that apply.

Grammar corrections

Pronunciation corrections

Feedback on content

Feedback on task achievement

Comments on areas to improve

8. Comments.

9. In previous terms, which type of feedback you think you mostly received? Tick all that apply.

Grammar corrections

Pronunciation corrections

Feedback on content

Overall feedback

Comments on areas to improve

10. Comments

11. How many times did you watch each feedback given in this manner? 
1 time only

2 times

3 or more

I didn't watch it

12. What did you do if you had questions or doubts about the feedback received?

13. Did it make you uncomfortable receiving feedback together with your Skype partner(s)? Yes

No, I think I can learn a lot from my partner's mistakes.

No, but I would have preferred a video directed only to me.

14. Comments.

15. Would you like to continue receiving feedback in this manner?

Yes

No

16. Comments.

17. Any other comments? 